\title{
PHENOLIC COMPOUNDS IN RED OAK AND SUGAR MAPLE LEAVES HAVE PROOXIDANT ACTIVITIES IN THE MIDGUT FLUIDS OF Malacosoma disstria AND Orgyia leucostigma CATERPILLARS
}

\author{
RAYMOND BARBEHENN,* SUSANNAH CHEEK, ADRIAN GASPERUT, \\ EMMA LISTER, and ROSALYN MABEN \\ Departments of Molecular, Cellular and Developmental Biology, Ecology and Evolutionary \\ Biology, University of Michigan, Ann Arbor, MI 48109-1048, USA
}

(Received October 14, 2004; accepted January 10, 2005)

\begin{abstract}
Phenolic compounds are generally believed to be key components of the oxidative defenses of plants against pathogens and herbivores. However, phenolic oxidation in the gut fluids of insect herbivores has rarely been demonstrated, and some phenolics could act as antioxidants rather than prooxidants. We compared the overall activities of the phenolic compounds in red oak (Quercus rubra) and sugar maple (Acer saccharum) leaves in the midgut fluids of two caterpillar species, Malacosoma disstria (phenolicsensitive) and Orgyia leucostigma (phenolic-tolerant). Three hypotheses were examined: (1) ingested sugar maple leaves produce higher levels of semiquinone radicals (from phenolic oxidation) in caterpillar midgut fluids than do red oak leaves; (2) O. leucostigma maintains lower levels of phenolic oxidation in its midgut fluids than does $M$. disstria; and (3) phenolic compounds in tree leaves have overall prooxidant activities in the midgut fluids of caterpillars. Sugar maple leaves had significantly lower ascorbate: phenolic ratios than did red oak leaves, suggesting that phenolics in maple would oxidize more readily than those in oak. As expected, semiquinone radicals were at higher steady-state levels in the midgut fluids of both caterpillar species when they fed on sugar maple than on red oak, consistent with the first hypothesis. Higher semiquinone radical levels were also found in $M$. disstria than in $O$. leucostigma, consistent with the second hypothesis. Finally, semiquinone radical formation was positively associated with two markers of oxidation (protein carbonyls and total peroxides). These results
\end{abstract}

* To whom correspondence should be addressed. E-mail: rvb@umich.edu 


\begin{abstract}
suggest that the complex mixtures of phenolics in red oak and sugar maple leaves have overall prooxidant activities in the midgut fluids of $M$. disstria and $O$. leucostigma caterpillars. We conclude that the oxidative defenses of trees vary substantially between species, with those in sugar maple leaves being especially active, even in phenolic-tolerant herbivore species.
\end{abstract}

Key Words-Prooxidant, phenolic compound, oxidation, caterpillar, Malacosoma disstria, Orgyia leucostigma, peroxide, semiquinone radical, protein carbonyl, red oak, Quercus rubra, sugar maple, Acer saccharum.

\title{
INTRODUCTION
}

The phenolic compounds produced by plants represent a diverse array of over 8000 known structures (Thompson, 1964; Harborne, 1985; Bravo, 1998; Vinson et al., 2001). Along with oxidative enzymes, such as polyphenol oxidases and peroxidases, phenolic compounds are generally considered to be key components of the oxidative defenses of plants against pathogens and herbivores (Duffey and Stout, 1996). The products and byproducts of phenol oxidation include semiquinone radicals, quinones, and reactive oxygen species (e.g., hydrogen peroxide and hydroxyl radicals), each of which can damage nutrients in the gut lumens of insect herbivores or produce cytotoxic effects in their tissues (Gant et al., 1988; Felton et al., 1989, 1992; Canada et al., 1990; Zheng et al., 1997; Thiboldeaux et al., 1998; Galati et al., 2002; Hagerman et al., 2003). Thus, the oxidation of phenolics is believed to be an important step contributing to their biological activity (Canada et al., 1990; Ahmad, 1992; Appel, 1993; Summers and Felton, 1994; Pardini, 1995; Barbehenn et al., 2003b).

The physiological roles played by ingested phenolics vary, however, depending upon their chemical structures and physicochemical environments (e.g., pH, redox potential, and concentrations of oxidases, oxidants, and antioxidants) (Larson, 1995; Metadiewa et al., 1999; Sugihara et al., 1999; Galati et al., 2002; Sakihama et al., 2002; Hagerman et al., 2003). For example, if certain phenolics scavenge free radicals or otherwise function as reducing agents and they have structures that form stable semiquinone or phenoxyl radicals, they can act as antioxidants (Buettner, 1993; Hagerman et al., 1998; Halliwell and Gutteridge, 1999). Indeed, recent evidence has suggested that low molecular weight phenolics may act as antioxidants in some caterpillars (Johnson and Felton, 2001).

In this study, electron paramagnetic resonance spectrometry (EPR) was used to measure the steady-state levels of semiquinone radicals (produced by the one-electron oxidation of di- or trihydroxy phenolics) in caterpillar midgut fluids. In order to distinguish between the overall prooxidant or antioxidant 
activities of foliar phenolics, semiquinone radical levels were measured in conjunction with two markers of oxidation (protein carbonyls and total peroxides). We reasoned that if ingested phenolics had an overall prooxidant activity in midgut fluids, a positive association would be observed between levels of semiquinone radicals and markers of oxidation. By contrast, if semiquinone radicals were formed during the protection of other molecules from oxidation, then an overall antioxidant activity would be indicated by a negative association. In support of this rationale, previous work has shown that tannic acid in an artificial diet acts as a prooxidant in the midgut fluids of two caterpillar species: high levels of semiquinone radicals were associated with increased levels of reactive oxygen species and markers of oxidation (Barbehenn et al., 2001, 2003b, unpublished data).

Phenolic compounds have a strong tendency to oxidize at the high $\mathrm{pH}$ found in many caterpillar midguts (ca. pH 10) unless there is sufficient ascorbate present to chemically reduce semiquinone radicals (Barbehenn et al., 2001, 2003b). Thus, the potential for foliar phenolics to oxidize in the midgut fluids of caterpillars was predicted by examining the ratio of ascorbate to total phenolics in red oak and sugar maple leaves (Barbehenn et al., 2003b). Based on our previous work on these tree species (Barbehenn et al., 2003a), sugar maple leaves were expected to contain low ratios of ascorbate:phenolics and to produce high levels of phenolic oxidation, while red oak leaves were expected to contain high ratios of ascorbate:phenolics and to produce low levels of phenolic oxidation following ingestion.

The two caterpillar species chosen for comparison were expected to differ in their abilities to handle ingested phenolics. Malacosoma disstria Hübner (Lasiocampidae), the forest tent caterpillar, is a phenolic-sensitive species that feeds on the spring foliage of a wide range of deciduous trees in North America (Stehr and Cook, 1968). Orgyia leucostigma Smith (Lymantriidae), the whitemarked tussock moth, is a phenolic-tolerant species that also feeds on a wide range of North American trees during spring and summer broods (Baker, 1972). The degree of phenolic tolerance ascribed to the two species is based primarily on the extent to which phenolics ingested in artificial diets are oxidized in their midguts and, in the case of $M$. disstria, the formation of pupal deformities (Karowe, 1989). O. leucostigma maintains lower levels of phenolic oxidation in its midgut fluids than does M. disstria (Barbehenn and Martin 1992, 1994; Barbehenn et al., 2001, 2003b), but little work has been done on the gut biochemistries of these herbivores on their host plants.

This study examined three hypotheses: (1) ingested sugar maple leaves produce higher levels of semiquinone radicals than red oak leaves; (2) $O$. leucostigma maintains lower levels of phenolic oxidation than $M$. disstria; and (3) phenolic compounds in tree leaves have overall prooxidant activities in the midgut fluids of caterpillars. 
Trees. Red oak (Quercus rubra L.) $(N=14)$ and sugar maple (Acer saccharum Marshall) $(N=12)$ were tagged at three sites in Ann Arbor, MI, USA, the University of Michigan campus, the Matthaei Botanical Garden, and the Kuebler-Langford Park. Twigs containing terminal leaf clusters from the sunlit side of trees were cut with a pole pruner. Twigs were selected haphazardly, but damaged or diseased leaves were avoided. They were placed in a flask of water and returned to the lab for feeding experiments or were placed in labeled plastic bags and kept on ice in the dark until extracted 2-4 hr later. Leaves were sampled on the 12th of June and the 10th of July 2003. In addition, preliminary measurements were made on a group of three red oak and sugar maple trees on the 14th of May. Leaf lengths were measured repeatedly in the study trees beginning in May to determine the time when leaf expansion was complete.

A representative leaf (e.g., excluding small or young terminal leaves) was selected from within each leaf cluster. These leaves were cut in half along the length of the midrib, and the thickened portion of the midrib was removed. Leaf halves were immediately weighed (200-800 mg), ground in liquid nitrogen, and extracted in $3.0 \mathrm{ml}$ of $5 \%(\mathrm{w} / \mathrm{v})$ metaphosphoric acid (containing $1 \mathrm{mM}$ EDTA; ambient oxygen) or nitrogen-purged ethanol (Barbehenn et al., 2003a). Samples were extracted for $30 \mathrm{~min}$ (ambient temperature) and then centrifuged (1000 $\mathrm{g}$, $5 \mathrm{~min}$ ). The extraction process was repeated, and supernatant solutions were pooled within samples. Ethanolic extracts were kept under a nitrogen atmosphere, and all samples were stored at $-80^{\circ} \mathrm{C}$ until they were analyzed. A second leaf from each cluster was weighed, after removing the midrib, and dried at $70^{\circ} \mathrm{C}$ for $3 \mathrm{~d}$ in an open glassine envelope. The water content of these leaves was used to estimate the percent dry weight (\%DW) of leaves used for chemical analysis.

Insects. The main comparisons between $M$. disstria and $O$. leucostigma were made in mid-June (on recently expanded leaves) and in mid-July (on mature leaves). M. disstria normally completes most of its development on expanding leaves, and EPR measurements were done to coincide with this period. M. disstria and O. leucostigma eggs were obtained from the Canadian Forrest Pest Management Institute (Sault Ste. Marie, Ontario, Canada). The diet for both species was prepared as described previously (Barbehenn et al., 2001), with the exceptions that linseed oil was substituted for wheat germ oil, methyl paraben was omitted, and sodium alginate was included ( $2.9 \%$ dry diet). Larvae were maintained in petri dishes in incubators (primarily at $23^{\circ} \mathrm{C}, 16-\mathrm{hr} \mathrm{L}, 8-\mathrm{hr}$ D) until the final-instar. Colonies of both species were maintained at $18^{\circ} \mathrm{C}$ when it was necessary to slow their growth to synchronize their developmental stages. Final-instar larvae were assigned at random to feed on red oak or sugar maple 
leaves collected from three trees of each species on the University of Michigan campus. The same trees and leaf-sampling protocol were used for all experiments. Twigs with attached leaves were placed in water in $15-\mathrm{ml}$ centrifuged tubes that were placed inside ventillated plastic boxes $(30 \times 19 \times 10 \mathrm{~cm})$. Leaves in June and July were coated with $200 \mu \mathrm{l}$ of a $70 \%$ acetone solution of sucrose ( $2 \%$ dry weight) to promote feeding. The percent dry weight of the added sucrose was calculated based on the dry weight of untreated leaves. A micropipet was used to dispense the solvent evenly across each leaf, placing the pipette tip parallel to the leaf surface to avoid scratching the leaf. Boxes were replaced in an incubator where larvae were fed for $2 \mathrm{~d}$. Freshly treated leaves were provided on the second day, using the same trees for each caterpillar species (but different trees from the previous day). On the third day of each experiment, midgut fluids were collected from dissected larvae, as described previously (Barbehenn et al., 2001). Gut fluid samples were kept under a nitrogen atmosphere at all times to avoid artifactual oxidation (Johnson and Barbehenn, 1999).

Chemical Analyses. Ascorbic acid was measured in metaphosphoric acid extracts using high-performance liquid chromatography (HPLC) (Lykkesfeldt et al., 1995; Barbehenn, 2003). Samples were stored for 1-2 mo before analysis. Total phenolics were measured in ethanol extracts using the Prussian blue assay (Price and Butler, 1977) as modified by Graham (1992), using gum arabic to stabilize the colored product. This redox assay is based on the formation of a colored complex (ferric ferrocyanide) upon the reduction of iron (Fe III) by phenolic compounds. Samples were stored for 1-3 mo before analysis. Samples were diluted 20-fold with nitrogen-purged ethanol before analysis. Purified tannic acid, composed primarily of tetra- to octagalloylglucose (J.-P. Salminen, unpublished data), was used to construct standard curves. All assays were scaled to $200 \mu \mathrm{l}$ to fit in a 96-well microplate, and absorbances were read at $655 \mathrm{~nm}$ with a Bio-Rad Benchmark microplate reader (Bio-Rad, Hercules, CA, USA). To correct total phenolics measurements for the absorbance caused by foliar ascorbate, a regression between ascorbate concentration and Prussian blue formation was determined. The Prussian blue absorbance contributed by foliar ascorbate in each sample was then subtracted from the total absorbance value for each of the samples. Ascorbate accounted for $30-40 \%$ of the "total phenolics" in oak and for $20 \%$ of the "total phenolics" in maple. The unknown phenolic compositions of the tree leaves precluded reporting phenolic concentrations on a molar basis, and therefore, all concentrations were expressed on a percent dry weight basis in purified tannic acid equivalents.

To provide a general indication of the accuracy of the Prussian blue assay, total phenolics were analyzed with HPLC or the acid-butanol method (for condensed tannins). A single sample of red oak and sugar maple leaves (including each of the trees used as food plants) was collected in mid-July 2004. 
Leaf samples were lyophilized, extracted in $70 \%$ aqueous acetone, and the extracts were analyzed with HPLC using a diode array detector (Salminen et al., 1999). Hydrolyzable tannins were calculated in pentagalloyl glucose equivalents (at $280 \mathrm{~nm}$ ), flavonoids in quercetin equivalents (at $349 \mathrm{~nm}$ ), chlorogenic acids in chlorogenic acid equivalents (at $315 \mathrm{~nm}$ ), coumaroylquinic acids in coumaric acid equivalents (at $315 \mathrm{~nm}$ ), and the remaining phenolics (other than condensed tannin) as gallic acid equivalents (at $280 \mathrm{~nm}$ ). Condensed tannins were measured with the acid-butanol method (Ossipova et al., 2001), using purified birch leaf-condensed tannins as a standard.

Protein carbonyls were measured in midgut fluids with the 2,4-dinitrophenylhydrazine (DNPH) method (Reznick and Packer, 1994; Quinlan and Gutteridge, 2000). Samples (50-110 mg) were extracted in $400 \mu \mathrm{lof} \mathrm{pH} 6.5$ phosphate buffer $(200 \mathrm{mM}$, nitrogen-purged) containing $20 \mathrm{mg}$ of hydrated polyvinylpolypyrrolidone (Sigma). Samples were collected from five to 11 replicate larvae from each insect species on each tree species on the 13th of June, and samples from 10 to 15 larvae were collected on the 15th of July $(O$. leucostigma) and 17 th of July ( $M$. disstria). All samples were stored under a nitrogen atmosphere at $-80^{\circ} \mathrm{C}$ until they were analyzed after 4-4.5 mo. Protein carbonyls were measured in thawed extracts (kept on ice) after treating 200 $\mu \mathrm{l}$ of the supernatant solutions with streptomycin sulfate $(22.2 \mu \mathrm{l} ; 10 \% \mathrm{w} / \mathrm{v}$ in $50 \mathrm{mM}, \mathrm{pH} 7.0$, HEPES buffer). After centrifugation $\left(8000 \mathrm{~g}, 5 \mathrm{~min}, 4^{\circ} \mathrm{C}\right)$, proteins remaining in the supernatant solution were precipitated with trichloroacetic acid $(100 \mu \mathrm{l}, 28 \% \mathrm{w} / \mathrm{v})$. Protein pellets were treated with $500 \mu \mathrm{l}$ of $7 \mathrm{mM}$ DNPH (Acros) prepared in $2 \mathrm{M}$ hydrochloric acid $\left(37^{\circ} \mathrm{C}, 15 \mathrm{~min}\right)$. Treated protein pellets were washed free of unbound DNPH and solubilized in a guanidine hydrochloride solution (6 M; Acros) as described by Quinlan and Gutteridge (2000). An extinction coefficient of 22,000/M for the DNPH protein carbonyl adduct at $370 \mathrm{~nm}$ was used to calculate protein carbonyl concentrations (Reznick and Packer, 1994; Quinlan and Gutteridge, 2000). Correction for interfering substances was made by running DNPH-free controls from each of the treatments. Protein concentrations in the sample supernatants were measured with the modified Bradford assay and quantified with a bovine serum albumin standard curve (Stoscheck, 1990). Protein carbonyl levels were expressed as nanomoles protein carbonyl per milligram protein.

Total peroxides (hydrogen peroxide and organic peroxides) were measured in methanol extracts with the FOX assay (Nourooz-Zadeh et al., 1994). M. disstria midgut contents (25-35 mg from the mid-midgut) were extracted in $1.0 \mathrm{ml}$ of $90 \%$ methanol (nitrogen-purged), and the midgut contents of $O$. leucostigma $(10-20 \mathrm{mg})$ were extracted in $0.5 \mathrm{ml}$ of $90 \%$ methanol. Following centrifugation $(8000 \mathrm{~g}, 3 \mathrm{~min}$ ), a $35-\mu \mathrm{l}$ aliquot of the supernatant solution was diluted with $70 \mu \mathrm{l}$ of $90 \%$ methanol. $M$. disstria ( $N=14-22 /$ tree species) were examined on the 18th of June and the 11th of July, and O. leucostigma 
( $N=14 /$ tree species) were examined on the 14th of July. The FOX reagent was prepared fresh daily using ambient oxygen solvents. All assays were scaled to fit in a 96-well microplate, and absorbances were read at $540 \mathrm{~nm}$ with a microplate reader. Measurements were made within a period of approximately $1 \mathrm{hr}$ from the time of dissection. A hydrogen peroxide standard curve was used to determine total peroxide concentrations.

Electron Paramagnetic Resonance Spectrometry. Midgut contents (20 mg) were dissected from larvae, alternating between the four caterpillar/tree species combinations. Midgut contents were extracted in $300 \mu \mathrm{l}$ of $\mathrm{pH} 10$ carbonate buffer $(70 \mathrm{mM})$ containing $10 \%(\mathrm{v} / \mathrm{v})$ dimethyl sulfoxide (nitrogen-purged). Samples in 2.0-ml microcentrifuge tubes were kept under a nitrogen atmosphere at all times. Samples were centrifuged for $1 \mathrm{~min}$ (approximately 10,000 $\mathrm{g}$, ambient temperature). Semiquinone radicals in supernatant solutions were measured with a Bruker EMX spectrometer (Bruker Instruments, Billerica, MA, USA), using the instrumental parameters described previously (Barbehenn et al., 2003b). The time between dissecting each caterpillar and starting an EPR scan was recorded. The area of each spectrum was quantified by double integration using WinEPR software (Bruker Instruments). The sizes of semiquinone radical spectra decreased above a threshold phenolic concentration in both midgut fluid samples and in standards, apparently from semiquinone radical disproportionation (unpublished data). Therefore, the EPR spectra from a range of sample dilutions of each sample type were measured to confirm that semiquinone radical intensities increased with increasing sample mass over the full range of sample masses used. Standard curves based on tannic acid were linear over a shorter range than was necessary for quantifying the large radical spectra produced by sugar maple phenolics. Therefore, semiquinone radical intensity was expressed as the double integral area/sample mass, where the double integral area is in arbitrary units determined by instrumental parameters. Semiquinone radical intensities could be compared across all sample types in this and in previous studies because the same instrumental parameters were used in all cases. Radical intensity measured as the double integral area per milligram is directly proportional to, but approximately 10 - to 17 -fold larger than, measurements of spectrum height per milligram used previously (Barbehenn et al., 2003b). The identity of semiquinone or ascorbyl radicals was based upon the comparison of their spectra with standards and spectra obtained previously under identical conditions (Barbehenn et al., 2003b). As observed previously, semiquinone radical spectra from sugar maple and red oak phenolics had sigmoidal line shapes similar to those of tannic acid standards.

To correct for the decay in radical spectra through time, regressions were plotted of radical intensity vs. time. Samples of the four treatment groups were run in the 15th and 16th of May (Figure 3). These regressions included three to four samples of each type that were rescanned once or twice to extend the time 
range over which data were collected. Based on these regressions, semiquinone radical intensities in May, June, and July were adjusted to the levels expected after a period of $5 \mathrm{~min}$. Time periods between extracting a sample and starting an EPR scan averaged $5.0( \pm 0.2 \mathrm{~min})$ in June and $5.2( \pm 0.3 \mathrm{~min})$ in July, necessitating only minimal adjustments to these data. Sample sizes in each experiment ranged from eight to 15 replicate larvae for each of the four treatment groups. Midgut fluids from all four treatment groups were examined on the 10th of June, and additional $M$. disstria and $O$. leucostigma larvae were examined on the 11th and the 14th of June, respectively. Midgut fluids from $M$. disstria and $O$. leucostigma larvae were also examined on the 11 th and the 14 th of July, respectively.

Statistical Analyses. Concentrations of phenolic compounds and ascorbate, and ascorbate:phenolic ratios in red oak and sugar maple were compared using nested ANOVA, with site nested within tree species, and repeated measures on individual trees (PROC MIXED) (SAS, 2000). Significant effects are reported in the results. Semiquinone radical intensities, peroxides, and protein carbonyls were compared using two-way ANOVA, with insect and tree species as main effects. In May, when multiple EPR runs were made through time on the same sample, only the first EPR run on each sample was included in the ANOVA. To compare regressions of semiquinone radical intensity on time in May (Figure $3 \mathrm{~A}, \mathrm{~B}$ ), entire data sets (including multiple scans per sample) were analyzed with ANCOVA using time as the covariate (SAS, 2000). The normality of residuals was tested using PROC UNIVARIATE (SAS, 2000). If residuals could not be normalized by transformation, the significance of main effects was determined by Kruskal-Wallis tests (Wilkinson, 2000). Pairwise differences between means were examined by differences of least-squares means generated by PROC MIXED (SAS, 2000), or by Kruskal-Wallis tests. No significant differences were observed between days in experiments that were run on more than $1 \mathrm{~d}$, and these data were combined for final analysis. The spatial separation of analytical equipment used in different experiments and the small sample volumes available necessitated performing separate experiments to measure each analyte in caterpillar midgut fluids. Thus, the associations between semiquinone radical formation and markers of oxidation were examined by plotting mean levels (Figure 5A, B). The associations between semiquinone radical intensities and protein carbonyl concentrations in the midgut fluids of $M$. disstria and $O$. leucostigma (Figure 5A) were examined with regressions (Wilkinson, 2000) and by ANCOVA, using semiquinone radical intensity as the covariate (SAS, 2000). Insufficient data were available to examine the association between semiquinone radical intensities and total peroxide concentrations in O. leucostigma statistically. However, a visual examination of this relationship in $M$. disstria and $O$. leucostigma (Figure 5B) suggested that a single linear regression for the two species was appropriate and sufficient to 
examine whether semiquinone radical intensities are positively or negatively associated with the formation of peroxides.

\section{RESULTS}

Sugar maple leaves contained lower levels of ascorbate and higher levels of phenolic compounds than did red oak leaves in mid-June (Figure 1A). Similar results were obtained in mid-July (Figure 1B), with the exception that ascorbate levels were not significantly different between the species. Nevertheless, ascorbate:phenolic ratios remained significantly lower in sugar maple leaves in June $(0.045 \pm 0.009)$ and July $(0.056 \pm 0.007)$ than in oak in June $(0.19 \pm 0.02)$ and
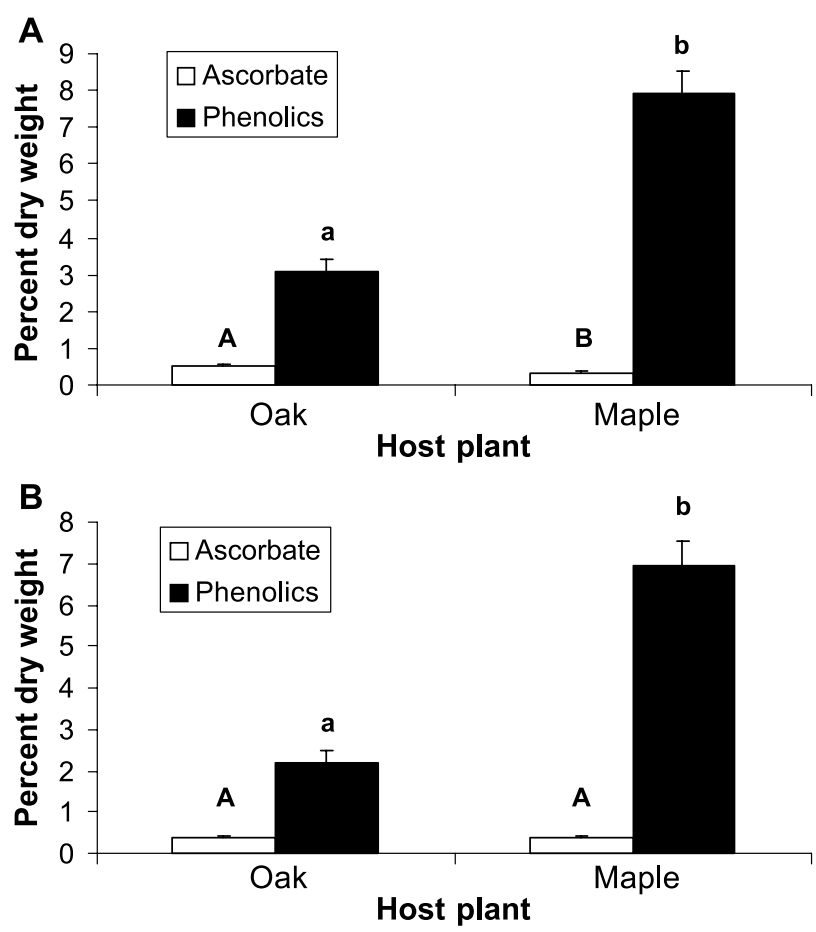

FIG. 1. Ascorbate and total phenolic levels in red oak (Q. rubra) and sugar maple $(A$. saccharum) leaves in mid-June (A) (soon after leaf expansion) and mid-July (B). Upper case letters that differ indicate significant differences between tree species for ascorbate $(P<0.05)$. Lower case letters that differ indicate significant differences between tree species for total phenolics. 
July $(0.25 \pm 0.06)(P<0.001)$. In a preliminary sample of leaves in May, ascorbate levels averaged $0.6 \%$ in both species. Total phenolics averaged 2.4 and 3.6\% in red oak and sugar maple, respectively, demonstrating that levels of total phenolics doubled as sugar maple leaves matured but remained at lower levels in red oak. Therefore, the early spring foliage of sugar maple used as food in this study also had a lower ascorbate:phenolic ratio $(0.17 \pm 0.01)$ than did red oak $(0.24 \pm 0.02)(P=0.050)$. Total phenolics in July 2004 , expressed as the sum of the individual phenolics, measured $3.4 \%$ in red oak and $13.0 \%$ in sugar maple. To the extent that year-to-year variation in the experimental trees was negligible, the Prussian blue assay appears to have underestimated total phenolics, but provided a useful estimate of the relative amounts of phenolics in the two tree species.
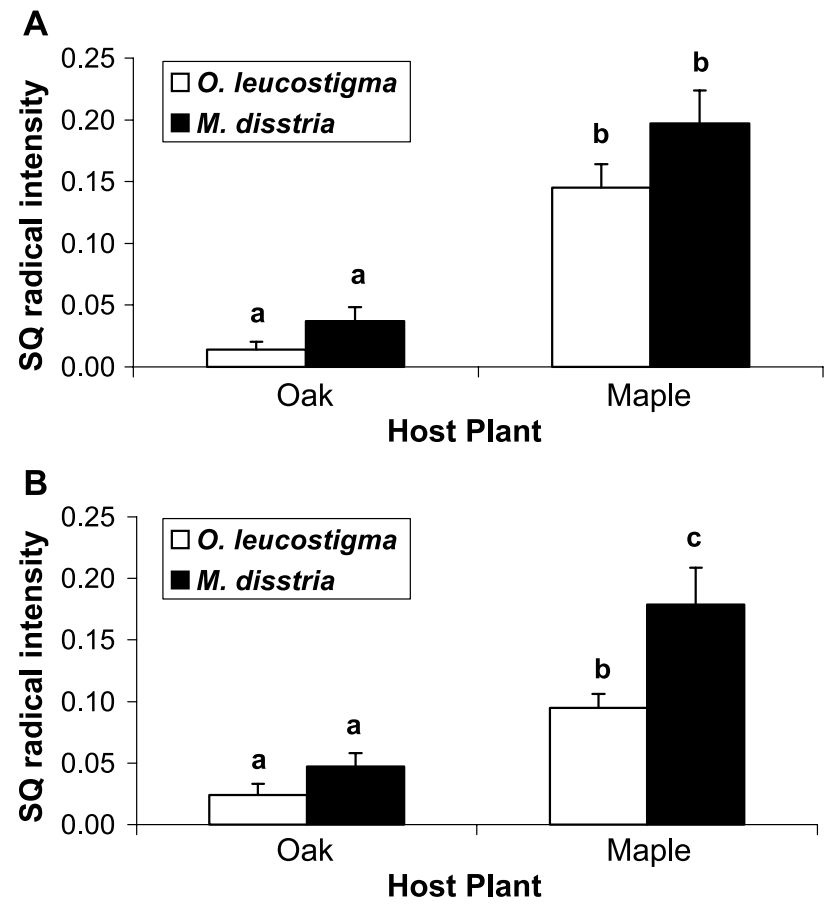

FIG. 2. Semiquinone (SQ) radical intensities in the midgut fluids of final-instar $O$. leucostigma and M. disstria larvae that fed on red oak or sugar maple leaves in mid-June (A) or in mid-July (B). Semiquinone radical intensity is defined as the double integral of the EPR spectrum per milligram sample, and all EPR spectra were standardized to a scan time beginning at $5 \mathrm{~min}$ after sample extraction. Different letters designate significant differences between the four treatments. 
Semiquinone radical intensities were higher in the midgut fluids of caterpillars that were fed on maple than on oak in June and July (Figure 2A, B) $(P<0.001$ for each month). Although semiquinone radical intensities were greater in $M$. disstria than in $O$. leucostigma in July $(P=0.056)$, they did not differ in June $(P=0.71)$. On early spring foliage, semiquinone radical intensities in $O$. leucostigma and $M$. disstria averaged $0.02 \pm 0.002 \mathrm{SE}$ and $0.14 \pm 0.02 \mathrm{SE}$ on oak, and $0.18 \pm 0.01 \mathrm{SE}$ and $0.30 \pm 0.02 \mathrm{SE}$ on maple, respectively. Thus, in May, higher semiquinone radical intensities were formed in maple-feeding caterpillars than in those feeding on oak $(P<0.001)$, and higher semiquinone radical intensities were formed in $M$. disstria than in $O$. leucostigma $(P<0.001)$. Generalizing across all 3 mo, higher semiquinone radical intensities were formed in maple-feeding caterpillars than in those
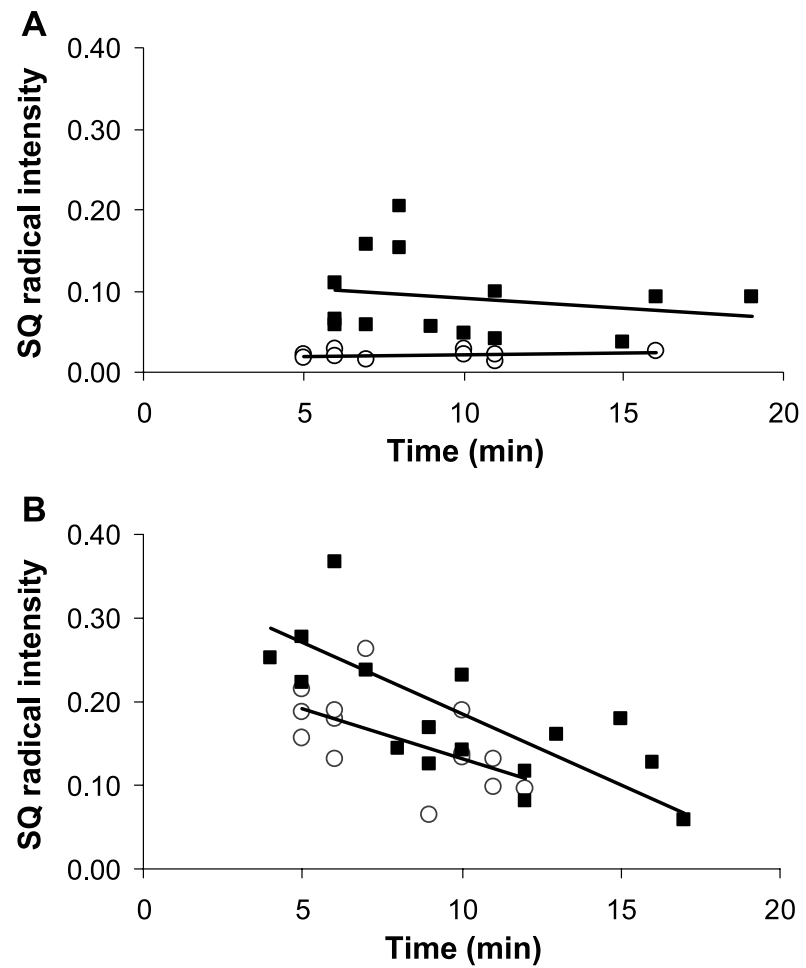

FIG. 3. Changes in semiquinone (SQ) radical intensity through time in the midgut fluids of final-instar $O$. leucostigma (open circles) and $M$. disstria (closed squares) on red oak (A) or sugar maple (B) in mid-May. Times indicate the number of minutes between the extraction of a sample and the beginning of an EPR scan of the sample. 
feeding on oak $(P<0.001)$, and they were higher in $M$. disstria than in $O$. leucostigma $(P=0.002)$. Semiquinone radical intensities were higher overall in May than in June $(P=0.002)$ or July $(P=0.001)$. In comparison with semiquinone radical intensities measured previously in $M$. disstria that were fed on an artificial diet containing a mixture of 5\% tannic acid and $2.3 \%$ ascorbate (Barbehenn et al., 2003b), radical intensities in M. disstria on sugar maple were roughly half as large.

Phenolic compounds in red oak leaves formed relatively stable semiquinone radicals in the midgut fluids of $O$. leucostigma and $M$. disstria (Figure 3A). Changes in semiquinone radical levels averaged only +0.0003 and -0.0025 intensity units/min in O. leucostigma and $M$. disstria, respectively. By comparison, semiquinone radicals from sugar maple phenolics had decay rates averaging -0.012 and -0.017 intensity units $/ \mathrm{min}$ in $O$. leucostigma and $M$. disstria, respectively (Figure 3B). Thus, semiquinone radicals from sugar maple
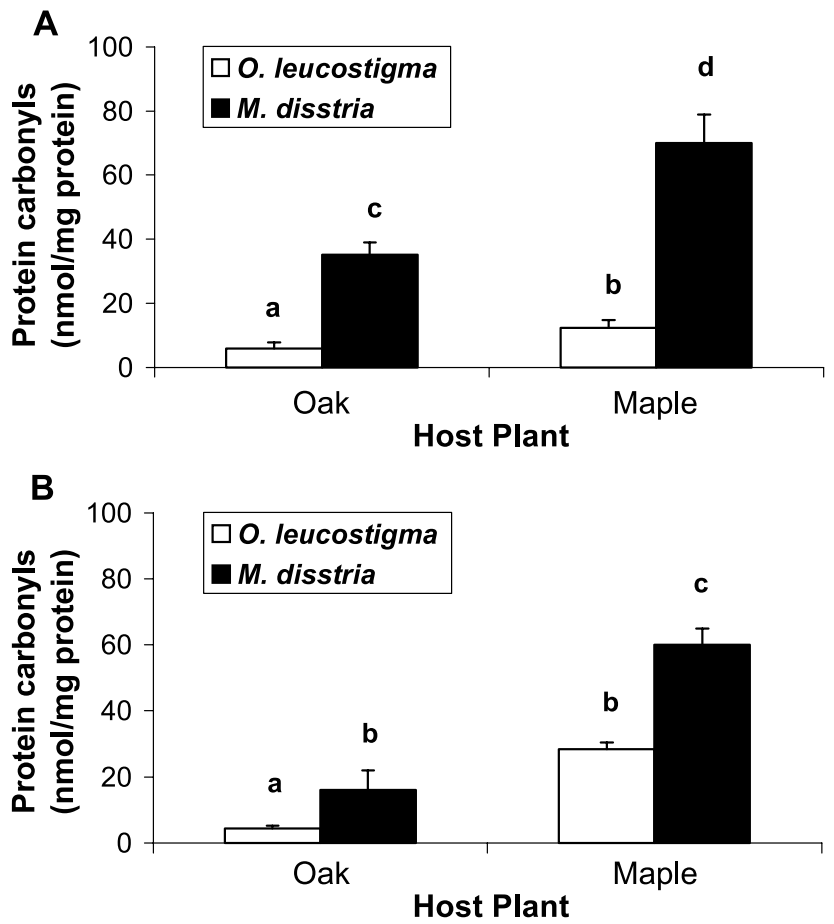

FIG. 4. Protein carbonyl levels in the midgut fluids of final-instar O. leucostigma and $M$. disstria larvae that fed on red oak or sugar maple leaves in mid-June (A) and in mid-July (B). Different letters designate significant differences between the four treatments. 
decayed more rapidly than did those from oak in $O$. leucostigma $(P<0.001)$ and showed a similar trend in $M$. disstria $(P=0.086)$. Rates of radical decay were not significantly different between the caterpillar species when they each fed on red oak $(P=0.508)$ or sugar maple $(P=0.792)$.

The formation of brown pigments, especially in larvae that fed on sugar maple, suggested that a substantial fraction of the semiquinone radicals oxidized further to form quinones and melanin-like compounds. The gut contents of oakfeeding larvae were commonly bright green, but some browning was observed in M. disstria in June and July. Browning was observed in the midgut fluids of many $M$. disstria larvae when they were fed on sugar maple in June and July (and to a lesser extent in May), but the contents of $O$. leucostigma were typically dark green in the spring and summer.
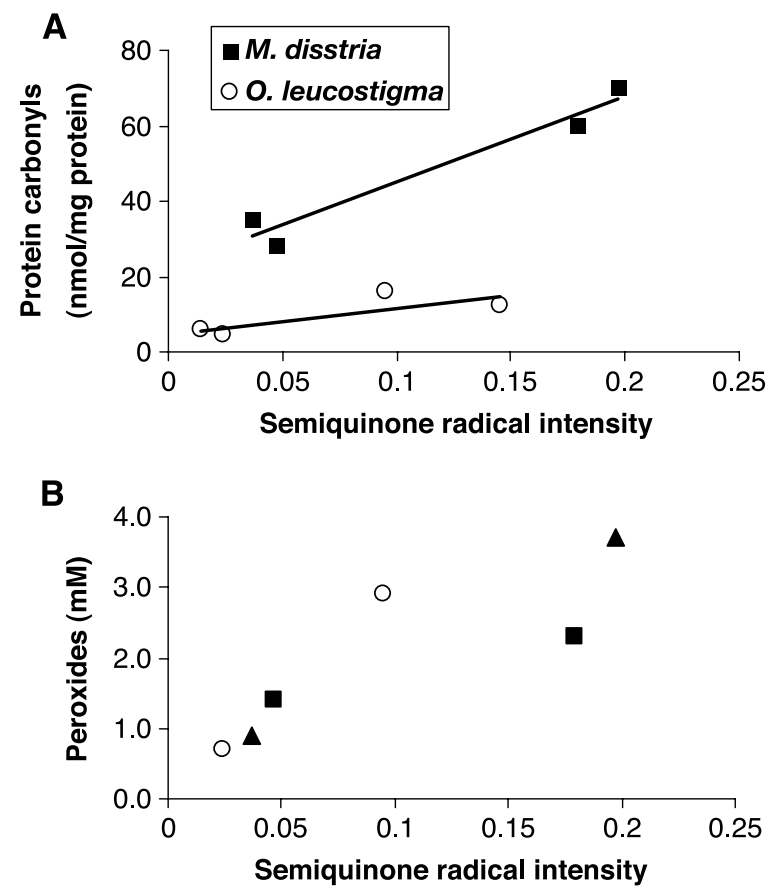

FIG. 5. Association between semiquinone radical intensities and protein carbonyl levels (A) and total peroxide levels (B) in the midgut fluids of final-instar O. leucostigma and $M$. disstria larvae that fed on red oak or sugar maple leaves in mid-June or in mid-July. In panel $\mathrm{B}$, closed squares $=M$. disstria in July, closed triangles $=M$. disstria in June, open circles $=O$. leucostigma in July. The lower means plotted for each insect species are from larvae that fed on red oak in June or July. 
Table 1. Total Peroxide Concentrations in the Midgut Fluids of Final-Instar O. leucostigma AND $M$. disstria LARVAE THAT FED ON RED OAK OR SUGAR MAPLE LEAVES ${ }^{a}$

\begin{tabular}{lllcr}
\hline Host plant & Insect species & Date & Peroxides $(\mathrm{mM})$ & $N$ \\
\hline Red oak & M. disstria & June 18 & $0.9 \pm 0.1^{\mathrm{a}}$ & 22 \\
Sugar maple & M. disstria & June 18 & $3.7 \pm 0.4^{\mathrm{b}}$ & 18 \\
Red oak & O. leucostigma & July 14 & $0.7 \pm 0.1^{\mathrm{a}}$ & 14 \\
Red oak & M. disstria & July 11 & $1.4 \pm 0.2^{\mathrm{b}}$ & 15 \\
Sugar maple & O. leucostigma & July 14 & $2.9 \pm 0.4^{\mathrm{d}}$ & 15 \\
Sugar maple & M. disstria & July 11 & $2.3 \pm 0.2^{\mathrm{c}}$ & 15 \\
\hline
\end{tabular}

${ }^{a}$ Data are presented as mean \pm SE. Summary statistics followed by different letters (within months) are significantly different $(P<0.05)$.

Protein in midgut fluids was oxidized to a greater extent in caterpillars that were fed on sugar maple than on red oak, both in June $(P<0.001)$ and July $(P=0.043)$ (Figure 4A, B). Protein carbonyl levels were also greater in $M$. disstria than in $O$. leucostigma in June $(P<0.001)$ and July $(P<0.001)$. Protein carbonyls in $M$. disstria were positively associated with semiquinone radical intensities in their midgut fluids $\left(R^{2}=0.95, P=0.025\right)$ (Figure $\left.5 \mathrm{~A}\right)$. In $O$. leucostigma, there was a much weaker association between protein carbonyls and semiquinone radical intensities $\left(R^{2}=0.63, P=0.21\right)$, although a nonsignificant result in this case could be due to a small sample size $(N=4)$. ANCOVA provided confirmation that, at a given semiquinone radical intensity, protein carbonyls were formed to a greater extent in $M$. disstria than in $O$. leucostigma $(P=0.043)$. Proteins also appeared to be oxidized at a higher rate in $M$. disstria than in $O$. leucostigma, as indicated by a significant interaction between species and semiquinone radical intensity $(P=0.046$; Figure 5A).

Total peroxide concentrations were consistently higher in larvae that were fed on sugar maple than on red oak (Table 1). However, peroxide levels in July were higher in O. leucostigma than in M. disstria on maple, the opposite of the result expected. Nevertheless, total peroxides in both caterpillar species were positively associated with semiquinone radical intensities in their midgut fluids $\left(R^{2}=0.72 ; P=0.033\right.$ for both species combined) (Figure 5B).

\section{DISCUSSION}

It has been hypothesized that phenolic compounds derive much of their antiherbivore activities from being "oxidatively activated" (Appel, 1993). However, 
few previous studies have clearly demonstrated that ingested phenolics in leaves oxidize in midgut fluids. Phenolic oxidation in the gut lumen has been suggested by studies that have measured (1) the loss of phenolics or increase in their oxidation products in frass (Felton et al., 1989; Barbehenn et al., 1996; Salminen and Lempa, 2002); (2) oxidative damage to the midgut epithelium (Summers and Felton, 1994; Bi and Felton 1995; Bi et al., 1997); or (3) the supression of ingested pathogens (Appel and Schultz, 1994; Hoover et al., 1998). However, in some of this previous work, including our own, it is likely that some fraction of phenolic oxidation occurred in frass after it left the low oxygen conditions in the gut, either from autooxidation or from polyphenol oxidase activity (Johnson and Barbehenn, 1999; Wang and Constabel, 2004). It is also possible that low molecular weight phenolics produce oxidative damage following their absorption into the midgut epithelium. The use of EPR spectrometry provides a direct measure of phenolic oxidation in the midgut fluids of caterpillars. Thus, a major finding in this study is the observation that phenolic compounds ingested in red oak and sugar maple leaves are oxidized in the midgut fluids of caterpillars. The overall prooxidant activity of these mixtures of phenolics is suggested by the positive relationships between semiquinone radical formation and two markers of oxidation in the midgut fluids from $M$. disstria and O. leucostigma. Although these results are correlative, it is noteworthy that previous experiments in which levels of phenolic compounds were controlled produced similar results; tannic acid ingested in an artificial diet also oxidized to produce elevated levels of semiquinone radicals, protein carbonyls, and peroxides, particularly in M. disstria (Barbehenn et al. 2001, 2003b, unpublished data). The results of the present study are consistent with two additional hypotheses: (1) the oxidation of phenolics and markers of oxidative damage are greater in the midgut fluids of caterpillars feeding on maple than in those feeding on oak; and (2) the levels of oxidation are greater in the phenolic-sensitive species $M$. disstria than in the phenolic-tolerant species $O$. leucostigma.

As expected, sugar maple leaves contain lower ascorbate:phenolic ratios and produce substantially higher semiquinone radical levels in caterpillar midgut fluids than red oak leaves. However, high levels of semiquinone radicals were also produced in the midgut fluids of both $M$. disstria and $O$. leucostigma when they ingested an artificial diet containing an ascorbate:gallic acid ratio of 0.21 (on a \%DW basis) (Barbehenn et al., 2003b). Therefore, differences in ascorbate:phenolic ratios alone cannot explain (1) why a similar ascorbate:phenolic ratio in red oak leaves $(0.25)$ produces a low level of semiquinone radicals in midgut fluids, (2) why high levels of semiquinone radicals are produced in larvae that feed on sugar maple in May (ascorbate:phenolics ratio of 0.17), or (3) why semiquinone radicals from sugar maple phenolics decay rapidly, while those from red oak are relatively stable in gut fluids. It appears likely that both the propensity of specific types of phenolics to oxidize and the stability of 
the semiquinone radicals formed also affect the extent of oxidative damage in midgut fluids. Sugar maple leaves analyzed from July of 2004 contained high levels of ellagitannins, condensed tannins, and gallotannins, while red oak leaves were rich in condensed tannins, but contained almost no measurable ellagitannins or gallotannins (J.-P. Salminen, unpublished data). This difference in phenolic composition, along with the differences in semiquinone radical intensity and decay rates between the two tree species, leads us to suspect that sugar maple phenolics are more prone to oxidize and to damage other biomolecules than are the phenolics in red oak leaves. Other components of the oxidative defenses of maple and oak leaves, such as their oxidative enzymes, could also contribute to the observed differences in the activities of ingested oak and maple phenolics.

The relatively high levels of semiquinone radicals produced in $M$. disstria and O. leucostigma in May compared to June and July suggest that feeding on spring foliage does not necessarily allow these herbivores to avoid the prooxidant activities of ingested phenolic compounds. It is well known that the phenolic compositions of tree leaves change seasonally, even in cases in which there is an apparent lack of change in total phenolic levels (e.g., Salminen et al., 2004). It would be of interest to examine whether the types of phenolic compounds in immature leaves produce higher semiquinone radical intensities than those in mature leaves and to confirm whether biomarkers of oxidation are also higher in May in maple-feeding caterpillars.

As noted above, the observation that phenolic compounds are oxidized more extensively in $M$. disstria than in $O$. leucostigma is consistent with previous work on the propensity of ingested phenolics to oxidize in these species (Barbehenn and Martin, 1992, 1994; Barbehenn et al., 2001, 2003a,b). Therefore, differences in the gut biochemistries of $M$. disstria and O. leucostigma that have been observed on artificial diets are relevant to the more complex mixtures of phenolic compounds found in their host plants. A key conclusion of these studies has been that $O$. leucostigma maintains a more efficient ascorbate recycling system than does $M$. disstria, thereby minimizing phenolic oxidation. Higher ascorbate concentrations are found in O. leucostigma than in M. disstria on artificial diets and on tree leaves in July, but not on immature leaves in the spring (Barbehenn et al., 2001, 2003a). Thus, we are unable to explain the lower levels of semiquinone radicals formed in O. leucostigma on the basis of higher ascorbate levels in all cases.

Were levels of semiquinone radicals and markers of oxidation sufficiently low in O. leucostigma to suggest that phenolic compounds in oak can act as antioxidants in the midgut lumen? An experiment to determine this, such as one in which phenolic-poor leaves were treated with different levels of oak phenolics and levels of markers of oxidation were negatively correlated with phenolic levels, has not been done. However, the low peroxide levels in the 
midgut fluids of caterpillars on artificial diets suggest that peroxide levels in the midgut fluids of $O$. leucostigma on oak were increased, rather than decreased, by oak phenolics. Peroxide levels in midgut fluids of both O. leucostigma and $M$. disstria on a phenolic-free diet were on the order of 50-100 $\mu \mathrm{M}$ (using the FOX and red ferrithiocyanate assays) and even peroxide levels measured on a diet containing 5\% tannic acid were well below the levels of total peroxides measured in O. leucostigma on oak (Barbehenn et al., 2001, unpublished data). Nevertheless, red oak does appear to be a relatively benign host plant in terms of its oxidative defenses for both species of caterpillars tested.

In the case of sugar maple, the oxidative damage it generates in caterpillars could potentially explain its poor host plant quality for $M$. disstria in its northern range (Nicol et al., 1997). Increases in both protein oxidation and peroxides are potentially harmful to insect fitness (Cadenas, 1995; Felton, 1996; Halliwell and Gutteridge, 1999). However, we are unaware of studies that have clearly shown a negative relationship between the oxidation of phenolic compounds in the gut fluids of insects and their performance. Such work is needed to examine the effectiveness of plant oxidative defenses against insect herbivores more closely.

Acknowledgments - We thank Michael M. Martin for suggesting revisions to our manuscript, Juha-Pekka Salminen for analyzing phenolic compounds with HPLC-DAD, Bob McCron for providing insect eggs, and David Borneman, Brian Klatt, and Marvin Pettway for permission to use trees at Kuebler-Langford Park, the Matthaei Botanical Gardens, and the University of Michigan, respectively. This work was supported by NSF grant IBN-9974583 to RVB.

\section{REFERENCES}

AHMAD, S. 1992. Biochemical defence of pro-oxidant plant allelochemicals by herbivorous insects. Biochem. Syst. Ecol. 20:269-296.

APPEL, H. M. 1993. Phenolics in ecological interactions: The importance of oxidation. J. Chem. Ecol. 19:1521-1552.

APPEL, H. M. and SCHULTZ, J. C. 1994. Oak tannins reduce effectiveness of Thuricide (Bacillus thuringiensis) in gypsy moth (Lepidoptera: Lymantriidae). J. Econ. Entomol. 87:1736-1742.

BAKER, W. L. 1972. Eastern Forest Insects. USDA Miscellaneous Publication no. 1175, Washington, DC..

BARBEHENN, R. V. 2003. Antioxidants in grasshoppers: Higher levels defend the midgut tissues of a polyphagous species than a graminivorous species. J. Chem. Ecol. 29:683-702.

BARBEHENN, R. V. and MARTIN, M. M. 1992. The protective role of the peritrophic membrane in the tannin-tolerant larvae of Orgyia leucostigma (Lepidoptera). J. Insect Physiol. 38:973-980.

BARbehenN, R. V. and MARTIN, M. M. 1994. Tannin sensitivity in Malacosoma disstria: Roles of the peritrophic envelope and midgut oxidation. J. Chem. Ecol. 20:1985-2001.

Barbehenn, R. V., Martin, M. M., and Hagerman, A. E. 1996. Reassessment of the roles of the peritrophic envelope and hydrolysis in protecting polyphagous grasshoppers from ingested hydrolyzable tannins. J. Chem. Ecol. 22:1911-1929. 
Barbehenn, R. V., Bumgarner, S. L., Roosen, E. F., and Martin, M. M. 2001. Antioxidant defenses in caterpillars: Role of the ascorbate-recycling system in the midgut lumen. J. Insect Physiol. 47:349-357.

BARBEHENN, R. V., WALKER, A. C., and UdDin, F. 2003a. Antioxidants in the midgut fluids of a tannin-tolerant and a tannin-sensitive caterpillar: Effects of seasonal changes in tree leaves. J. Chem. Ecol. 29:1099-1116.

Barbehenn, R. V., Poopat, U., and Spencer, B. 2003b. Semiquinone and ascorbyl radicals in the gut fluids of caterpillars measured with EPR spectrometry. Insect Biochem. Mol. Biol. $33: 125-130$.

BI, J. L. and FeLton, G. W. 1995. Foliar oxidative stress and insect herbivory: Primary compounds, secondary metabolites, and reactive oxygen species as components of induced resistance. J. Chem. Ecol. 21:1511-1530.

Bi, J. L., Murphy, J. B., and Felton, G. W. 1997. Antinutritive and oxidative components as mechanisms of induced resistance in cotton to Helicoverpa zea. J. Chem. Ecol. 23:97-117.

BRAVO, L. 1998. Polyphenols: Chemistry, dietary sources, metabolism, and nutritional significance. Nutr. Rev. 56:317-333.

BuETTNER, G. 1993. The pecking order of free radicals and antioxidants: Lipid peroxidation, $\alpha$-tocopherol, and ascorbate. Arch. Biochem. Biophys. 300:535-543.

CADENAS, E. 1995. Mechanisms of oxygen activation and reactive oxygen species detoxification, pp. 1-61, in S. Ahmad (ed.). Oxidative Stress and Antioxidant Defenses in Biology. Chapman and Hall, New York.

Canada, A. T., Giannella, E., Nguyen, T. D., and Mason, R. P. 1990. The production of reactive oxygen species by dietary flavonols. Free Radic. Biol. Med. 9:441-449.

DufFey, S. S. and Stout, M. J. 1996. Antinutritive and toxic components of plant defense against insects. Arch. Insect Biochem. Physiol. 32:3-37.

Felton, G. W. 1996. Nutritive quality of plant protein: Sources of variation and insect herbivore responses. Arch. Insect Biochem. Physiol. 32:107-130.

Felton, G. W., Donato, K. K., DEL Vecchio, R. J., and DufFey, S. S. 1989. Activation of plant polyphenol oxidases by insect feeding damage reduces the nutritive quality of foliage. J. Chem. Ecol. 15:2667-2694.

Felton, G. W., Donato, K. K., Broadway, R. M., and Duffey, S. S. 1992. Impact of oxidized plant phenolics on the nutritional quality of dietary protein to a noctuid herbivore. J. Insect Physiol. 38:277-285.

Galati, G., SAbZeVari, O., Wilson, J. X., and O'Brien, P. J. 2002. Prooxidant activity and cellular effects of the phenoxyl radicals of dietary flavonoids and other polyphenolics. Toxicology 177:91-104.

Gant, T. W., Ramakrishna, R., Mason, R. P., and Cohen, G. M. 1988. Redox cycling and sulphydryl arylation; their relative importance in the mechanism of quinone cytotoxicity to isolated hepatocytes. Chem.-Biol. Interact. 65:157-173.

Graham, H. D. 1992. Stabilization of the Prussian blue color in the determination of polyphenols. J. Agric. Food Chem. 40:801-805.

Hagerman, A. E., Riedl, K. M., Jones, G. A., Sovik, K. N., Ritchard, N. T., Hartzfeld, P. W., and RIECHEL, T. L. 1998. High molecular weight plant polyphenolics (tannins) as biological antioxidants. J. Agric. Food Chem. 46:188-189.

Hagerman, A. E., Dean, R. T., and Davies, M. J. 2003. Radical chemistry of epigallocatechin gallate and its relevance to protein damage. Arch. Biochem. Biophys. 414:115-120.

Halliwell, B. and Gutteridge, J. M. C. 1999. Free Radicals in Biology and Medicine. Oxford University Press, Oxford.

Harborne, J. B. 1985. Phenolics and plant defence, pp. 393-408, in C. F. Van Sumere and P. J. Lea (eds.). The Biochemistry of Plant Phenolics. Oxford University Press, New York. 
Hoover, K., Kishida, K. T., Digiorgio, L. A., Workman, J., Alaniz, S. A., Hammock, B. D., and DuFFEY, S. S. 1998. Inhibition of baculoviral disease by plant-mediated peroxidase activity and free radical generation. J. Chem. Ecol. 24:1949-2001.

JOHNSON, K. S. and BARBEHENN, R. V. 1999. Oxygen levels in the gut lumens of herbivorous insects. J. Insect Physiol. 46:897-903.

Johnson, K. S. and Felton, G. W. 2001. Plant phenolics as dietary antioxidants for herbivorous insects: A test with genetically modified tobacco. J. Chem. Ecol. 27:2579-2597.

KAROWE, D. N. 1989. Differential effect of tannic acid on two tree-feeding Lepidoptera: Implications for theories of plant anti-herbivore chemistry. Oecologia 80:507-512.

LARSON, R. A. 1995. Antioxidant mechanisms of secondary natural products, pp. 210-237, in S. Ahmad (ed.). Oxidant-Induced Stress and Antioxidant Defenses in Biology. Chapman and Hall, New York.

LyKKesfeldt, J., LOFT, S., and Poulsen, H. E. 1995. Determination of ascorbic acid and dehydroascorbic acid in plasma by high-performance liquid chromatography with coulometric detection-Are they reliable biomarkers of oxidative stress? Anal. Biochem. 229:329-335.

Metadiewa, D., Jaiswal, A. K., Cenas, N., Dickancaite, E., and Segura-Auilar, J. 1999. Quercetin may act as a cytotoxic prooxidant after its metabolic activation to semiquinone and quinoidal product. Free Radic. Biol. Med. 26:107-116.

Nicol, R. W., Arnason, J. T., Helson, B., and Abou-Zaid, M. M. 1997. Effect of host and nonhost trees on the growth and development of the forest tent caterpillar, Malacosoma disstria Hübner (Lepidoptera: Lasiocampidae). Can. Entomol. 129:995-1003.

Nourooz-Zadeh, J., Tajaddini-Sarmadi, J., and WolfF, S. P. 1994. Measurement of plasma hydroperoxide concentrations by the ferrous oxidation-xylenol orange assay in conjunction with triphenylphosphine. Anal. Biochem. 220:403-409.

Ossipova, S., Ossipov, V., Haukioja, E., Loponen, J., and Pihlaja, K. 2001. Proanthocyanidins of mountain birch leaves: Quantification and properties. Phytochem. Anal. 12:128-133.

PARDINI, R. S. 1995. Toxicity of oxygen from naturally occurring redox-active pro-oxidants. Arch. Insect Biochem. Physiol. 29:101-118.

PricE, M. P. and BUtLeR, L. G. 1977. Rapid visual estimation and spectrophotometric determination of tannin content of Sorghum grain. J. Agric. Food Chem. 25:1268-1273.

Quinlan, G. J. and GutTERIDGE, J. M. C. 2000. Carbonyl assay for oxidative damage to proteins, pp. 257-258, in N. Taniguchi and J. M. C. Gutteridge (eds.). Experimental Protocols for Reactive Oxygen and Nitrogen Species. Oxford University Press, Oxford.

REZNICK, A. Z. and PACKER, L. 1994. Oxidative damage to proteins: Spectrophotometric method for carbonyl assay. Methods Enzymol. 233:357-371.

Sakinama, Y., Cohen, M. F., Grace, S. C., and Yamasaki, H. 2002. Plant phenolic antioxidant and prooxidant activities: Phenolics-induced oxidative damage mediated by metals in plants. Toxicology 177:67-80.

SALMINEN, J.-P. and LEMPA, K. 2002. Effects of hydrolyzable tannins on a herbivorous insect: Fate of individual tannins in insect digestive tract. Chemocology 12:203-211.

SAlminen, J.-P., Ossipov, V., Loponen, J., Haukioja, E., and Pihlaja, K. 1999. Characterization of hydrolyzable tannins from leaves of Betula pubescens by high-performance liquid chromatography-mass spectrometry. J. Chromatrogr., A 864:283-291.

Salminen, J.-P., Roslin, T., Karonen, M., Sinkkonen, J., Pihlaja, K., and Pulkkinen, P. 2004. Seasonal variation in the content of hydrolysable tannins, flavonoid glycosides, and proanthocyanidins in oak leaves. J. Chem. Ecol. 30:1675-1693.

SAS InSTITUTE. 2000. The SAS System for Windows. Version 8e. SAS Institute, Cary, NC, USA.

STEHR, W. F. and CoOK, E. F. 1968. A revision of the genus Malacosoma Hübner in North America (Lepidoptera: Lasiocampidae): Systematics, biology, immatures, and parasites. Smithsonian Inst., U.S. Nat. Mus. Bull. no. 276. 
Stoscheck, C. M. 1990. Increased uniformity in the response of the Coomassie blue G protein assay to different proteins. Anal. Biochem. 184:111-116.

Sugihara, N., ARAKAWA, T., OHNISHI, M., and FurUnO, K. 1999. Anti- and pro-oxidative effects of flavonoids on metal-induced lipid hydroperoxide-dependent lipid peroxidation in cultured hepatocytes loaded with $\alpha$-linolenic acid. Free Radic. Biol. Med. 27:1313-1323.

Summers, C. B. and Felton, G. W. 1994. Prooxidant effects of phenolic acids on the generalist herbivore Helicoverpa zea (Lepidoptera: Noctuiidae): Potential mode of action for phenolic compounds in plant anti-herbivore chemistry. Insect Biochem. Mol. Biol. 24:943-953.

ThiboldeauX, R. L., Lindroth, R. L., and Tracy, J. W. 1998. Effects of juglone (5-hydroxy-1,4naphthoquinone) on midgut morphology and glutathione status in Saturniid moth larvae. Comp. Biochem. Physiol. 120:481-487.

THOMPSON, R. H. 1964. Structure and reactivity of phenolic compounds, pp. 1-32, in J. B. Harborne (ed.). Biochemistry of Phenolic Compounds. Academic Press, New York.

Vinson, J. A., Proch, J., and Bose, P. 2001. Determination of quantity and quality of polyphenol antioxidants in foods and beverages. Methods Enzymol. 335:103-114.

Wang, J. and Constabel, C. P. 2004. Polyphenol oxidase overexpression in transgenic Populus leaves enhances resistance to forest tent caterpillar (Malacosoma disstria) herbivory. Planta 220:87-96.

WILKINSON, L. 2000. SYSTAT: The System for Statistics. SYSTAT, Inc., Evanston, IL.

ZheNG, J., ChO, M., JONES, A. D., and HAMMOCK, B. D. 1997. Evidence of quinone metabolites of naphthalene covalently bound to sulfur nucleophiles of proteins of murine clara cells after exposure to napthalene. Chem. Res. Toxicol. 10:1008-1014. 